\title{
Posterior Gastric Perforation in Liberia: A Case Report and Review of the Literature
}

\author{
Edet Ikpi 1,2*, Solomane Konneh¹, Bashir Yunusa1,2, Ansumana Camara', Swaliho Sheriff', \\ Romel Chinneh1, David Alele ${ }^{1,2}$
}

${ }^{1}$ Department of Surgery, JFK Memorial Hospital, Monrovia, Republic of Liberia

${ }^{2}$ Department of Surgery, Icahn School of Medicine, Mount Sinai, New York, USA

Email:^eeikpi@yahoo.com

How to cite this paper: Ikpi, E., Konneh, S., Yunusa, B., Camara, A., Sheriff, S., Chinneh, R. and Alele, D. (2018) Posterior Gastric Perforation in Liberia: A Case Report and Review of the Literature. Health, 10, 1342-1348.

https://doi.org/10.4236/health.2018.1010103

Received: August 26, 2018

Accepted: October 16, 2018

Published: October 22, 2018

Copyright $\odot 2018$ by authors and Scientific Research Publishing Inc. This work is licensed under the Creative Commons Attribution International License (CC BY 4.0).

http://creativecommons.org/licenses/by/4.0/

\begin{abstract}
Background: The incidence of posterior gastric perforation worldwide is low; the literature has no previous record of its occurrence in Liberia. The diffuse symptoms of a perforated posterior gastric ulcer, delay by patients before they present to hospital, and the lack of skilled personnel and facilities in Liberia to diagnose and treat this condition increase the mortality associated with posterior gastric perforation. Objective: To report the first case of posterior gastric perforation encountered in Liberia. Materials and Method: Case report. Case Presentation/Report: A 44 year old male was referred to John F. Kennedy Memorial Hospital (Liberia's principal teaching hospital) with a diagnosis of gastritis after six days of worsening epigastric pain. He had a history of NSAID use for a chronic leg and foot ulcer. Physical examination revealed a moderately distended, markedly tender abdomen characterized by guarding, rigidity and low-pitched bowel sounds. Patient was resuscitated with intravenous fluids, antibiotics and analgesics. An emergency exploratory laparotomy subsequently performed revealed a large collection of purulent peritoneal fluid, a $3 \times 4 \mathrm{~cm}$ perforation on the posterior wall of the stomach and a $3 \times 2.5 \mathrm{~cm}$ perforation of the transverse mesocolon. The perforations were repaired and the patient recovered satisfactorily. Conclusion: Though relatively rare and associated with a high morbidity and mortality, this case report shows that the paucity of reported cases of posterior gastric perforation may also be attributable to lack of specialist staff with capacity for clinical diagnosis and surgical intervention in a resource poor setting. Identifying patients with gastric perforation and having the skill to repair the perforations significantly enhance the clinical outcome.
\end{abstract}

\section{Keywords}

Perforation, Ulcer, Gastric, Posterior 


\section{Introduction}

Posterior perforation of gastric ulcer is an uncommon clinical condition. Its occurrence may be masked by the diffuse nature of symptoms of this pathology leading to delays in patient presentation to the surgeon and attendant increase in morbidity and mortality. The more common type of perforation associated with the stomach is an anterior perforation occurring at the pyloro-duodenal area [1]. Gastric tissue is adapted to withstand the digestive action of gastric juice normally secreted by the stomach; however, the tolerance of gastric tissue is adversely affected by infection with $H$. pylori, cigarette smoking and ingestion of non-steroidal anti-inflammatory drugs.

A high degree of suspicion is required to make a pre-operative diagnosis of posterior gastric perforation; most times the diagnosis is made intra-operatively. Early intervention in these cases is imperative to improve patient's chances of survival. In resource poor settings, delay in presentation to the hospital and in making the decision to explore the patient because of the lack of skilled manpower, pose a critical challenge. This case report therefore seeks to benchmark this first ever recorded incidence of posterior gastric perforation in Liberia.

\section{Case Presentation}

A 44 year old Liberian male was referred to John F. Kennedy Memorial Hospital with a diagnosis of gastritis. The patient had presented to another hospital six days after he developed worsening epigastric pain. He had had generalized abdominal pain which was worse around the umbilicus with associated bouts of non-projectile, postprandial vomiting and constipation two days after the onset of his symptoms. The patient had a history of a chronic right leg and foot ulcer for which he took non-steroidal anti-inflammatory drugs (NSAIDs) and multiple antibiotics. He reported no previous history of gastritis, peptic ulcer disease, diabetes or hypertension.

Physical examination revealed an unkempt, pale and dehydrated middle-aged man in painful distress. His vital signs were a heart rate of $101 \mathrm{bpm}$, blood pressure $156 / 103 \mathrm{~mm} \cdot \mathrm{Hg}$, respiratory rate $22 \mathrm{bpm}$ and temperature of $38.5^{\circ} \mathrm{C}$. The abdomen was moderately distended, diffusely tender with guarding and rigidity. Bowel sounds were low-pitched. The digital rectal examination was normal. A dry, healing chronic ulcer was seen on the dorsum of the right foot. Preliminary differential diagnosis included perforated peptic ulcer disease, ruptured appendicitis, and intestinal perforation due to typhoid fever. The WIDAL and H. pylori tests were negative. His $\mathrm{Hb}$ was $18.3 \mathrm{~g} / \mathrm{dl}$ and urinalysis was normal. Plain abdominal $\mathrm{x}$-rays in the erect and supine positions were diagnostic of gastrointestinal perforation with air under the right hemi-diaphragm (Figure 1). Abdomino-pelvic ultrasound scan showed free intraperitoneal fluid collection (images could not be preserved). No further laboratory work-up was done due to limited laboratory resources.

The patient was resuscitated with intravenous fluids. Nasogastric and urethral 


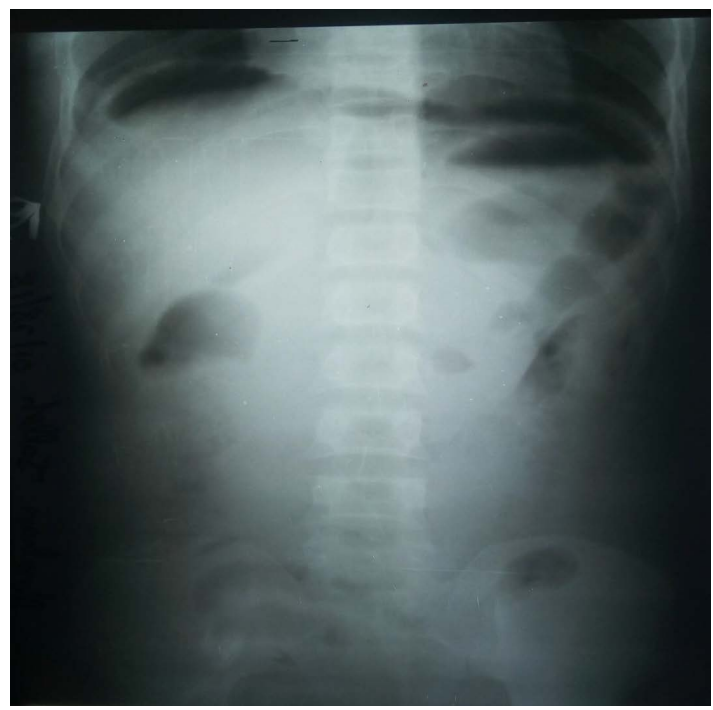

Figure 1. Plain erect abdominal x-ray showing collection of gas under the diaphragm.

catheters were passed. Intravenous broad spectrum antibiotics and analgesics were administered and an emergency exploratory laparotomy done. Findings at surgery included a $3 \mathrm{~cm} \times 4 \mathrm{~cm}$ perforation on the posterior wall of the stomach (Figure 2) and a $3 \mathrm{~cm} \times 2.5 \mathrm{~cm}$ perforation of the transverse mesocolon (Figure 3). Over 1.5 litres of purulent fluid were drained from the peritoneum. The anterior surface of the stomach, the duodenum and the rest of the gastrointestinal tract was intact.

A biopsy of the edge of the gastric defect was taken and a two-layer repair of the gastric perforation was done and protected with an omental patch (Figure 4). The defect in the transverse mesocolon was repaired and the peritoneal cavity lavaged. The abdomen was drained and closed. The patient recovered satisfactorily and upon discharged after 7 days was placed on proton pump inhibitors etc. The histology result of the gastric wall biopsy later returned as normal gastric histology.

He has returned to clinic for follow up and his condition has remained satisfactory six months after discharge.

\section{Discussion}

Four million people are affected globally by peptic ulcer diseases every year [2]; of the $10 \%-20 \%$ of those patients who get complicated, $2 \%-14 \%$ perforate [3]. Perforation remains the most important fatal complication of peptic ulcer disease [4]. Perforated gastric ulcer is relatively rare and when it occurs, is usually in the anterior aspect of the stomach [5]. Approximately $5 \%-8 \%$ of ulcers lie in the posterior wall of the body of the stomach and untreated, posterior ulcers may also perforate. Posterior perforation, however, is rare [6]. Wong, et al. in 2003 reported only 9 cases of posterior peptic ulcer perforation over a 12 year period in Singapore. Hamilton Bailey reported one posterior gastric ulcer in his 


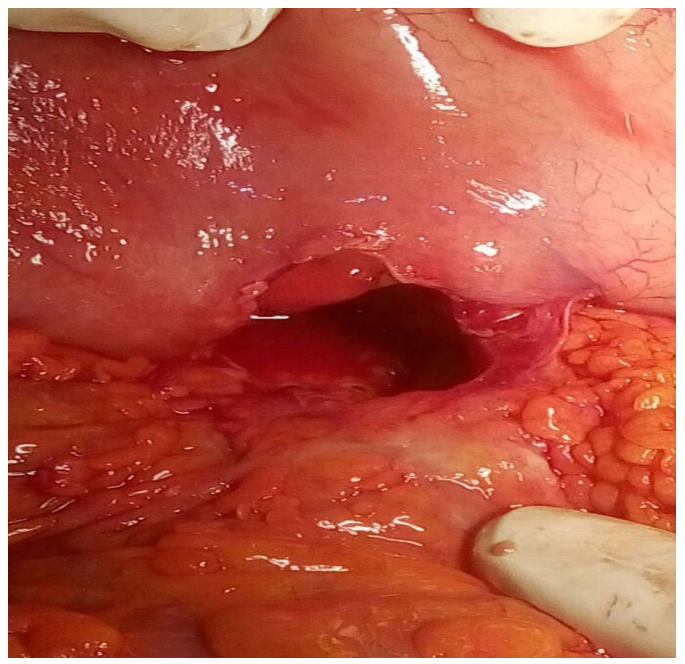

Figure 2. Giant perforation $(4 \mathrm{~cm} \times 3 \mathrm{~cm})$ on posterior wall of body of stomach.

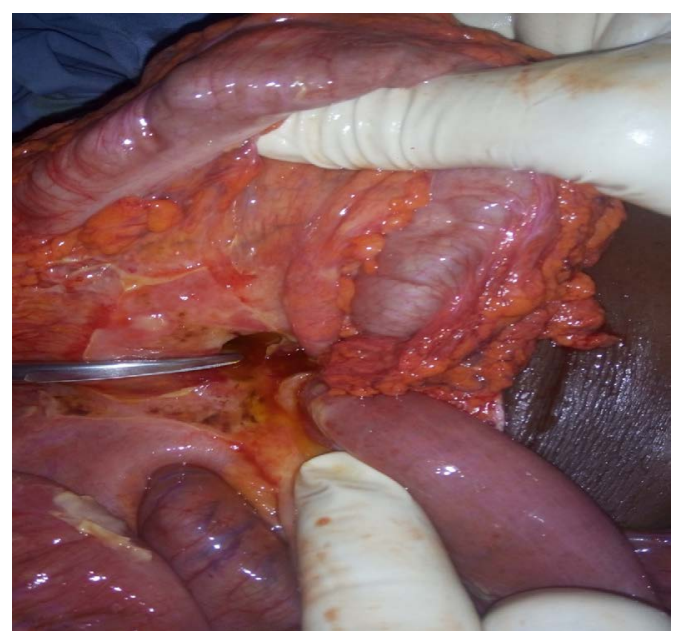

Figure 3. Perforation of the transverse mesocolon measuring $3 \times 2.5 \mathrm{~cm}$.

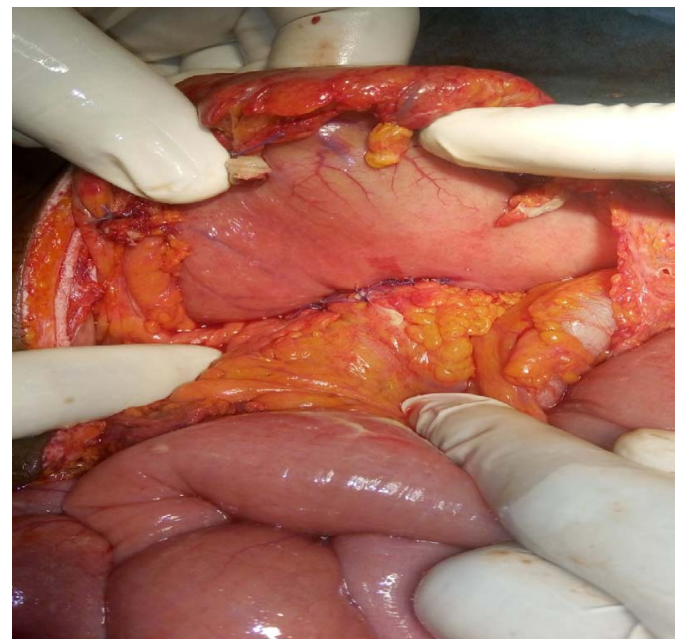

Figure 4. Two layers repair and omental patch. 
case series of 125 consecutive operations for perforated peptic ulcers. Helicobacter pylori infection, smoking, the use of NSAIDS, chronic stress, and advanced age ( $>60$ years) are the main predisposing factors for peptic ulcer perforation [7] [8].

The final common pathway to ulcer formation is acid-peptic injury of mucosal barrier. Thus, the adage "no acid, no ulcer" remains true. Posterior peptic ulcer perforation may be as a result of the above conditions or as a result of malignancy. When perforation occurs, it usually opens into the lesser sac or penetrates into the retroperitoneal space [9] [10]. Peptic digestion of surrounding tissues may lead to pancreatitis, biliary peritonitis or massive upper gastro-intestinal bleeding, particularly if the ulcer results in erosion into the inferior vena cava. Local inflammatory reaction may lead to fibrosis of the surrounding tissue.

Our patient, a $44 \mathrm{yr}$ old male, falls within the age range of $40-83$ reported by Wong [10], Badawy [11] and Afolayan [12]. His presentation with insidious abdominal pain which became generalized, followed by constipation and vomiting over a 6 day period is less dramatic compared to the more common anterior gastric perforation [13]. His consumption of alcohol, illicit drugs and the smoking of different brands of tobacco including marijuana, may have exacerbated an undiagnosed peptic ulcer disease resulting in perforation. Symptoms of bowel obstruction may sometimes be seen in cases of gastric perforation as reported in $25 \%$ of the cases reviewed by Wong. Coming to a definite pre-operative diagnosis therefore can pose a great challenge, an experience shared by other authors.

Although referred as a case of gastritis, our patient had no prior history of peptic ulcer disease. In the cases seen by Wong, Badawy and Afolayan, peptic ulcer disease was not entertained as a pre-existing pathology. Abdominal distension, generalized abdominal tenderness and board-like rigidity suggestive of peritonitis, which our patient presented with, is consistent with similar findings by Badawy and Afolayan. However, Wong et al. could not elicit the sign of peritonitis in $25 \%$ of their cases making the preoperative diagnosis of posterior gastric perforation even more difficult.

Abdominal x-ray findings of pneumo-peritoneum is pathognemonic of gastro-intestinal perforation in $67 \%-80.18 \%$ of the cases [14]. Pre-op diagnosis of peritonitis secondary to a perforated viscus can be made in most patients as corroborated by Badawy, Afolayan and 75\% of Wong's cases.

The treatment of choice for all patients with suspected gastric perforation is Emergency exploratory laparotomy [15]. Massive peritoneal contamination can complicate gastric perforation and requires diligent peritoneal lavage. Wong and Afolayan reported generalized peritoneal contamination in $66 \%$ of their patients. Pus collection in the lesser peritoneal sac is a common feature when the gastro-colic omentum is intact. We however found no pus collecting in the lesser sac of our patient possibly because of a $3 \times 2.5 \mathrm{~cm}$ perforation in the transverse meso-colon of our patient through which gastric content may have spread to the greater peritoneal cavity. 
A biopsy of the ulcer margins is imperative to establish the histological diagnosis. Repair of the perforation is usually done as a simple double layer closure reinforced with an omental patch. There is some controversy whether repaired large ulcers such as our patient had, should routinely be accompanied by a feeding jejunostomy because of the risk for re-leak when a simple closure with omental patch alone is performed [16]. Despite the large ulcer sizes encountered by Badawi, Afoloyan and our case, leakage from the repair site was not recorded. Our patient's post-operative course was uneventful and he was discharged home one week after surgery.

\section{Conclusions}

Posterior perforation of gastric ulcer is a rare clinical condition with very few cases documented in the literature. To our knowledge, only two cases have been reported in Africa. Our patient is possibly the third case reported in Africa and the second in West Africa. A high index of suspicion and deliberate access to the lesser sac through the gastro-colic ligament is necessary to discover these ulcers.

In most parts of Africa like Liberia, the mortality from gastric perforation is high because of the paucity of surgical care. International programs which support the deployment of specialist faculty to countries with severe shortages of health man-power can make an inestimable impact on health care delivery of such countries.

Increasing public awareness and encouragement of early presentation to the specialist centre holds the key to increasing the number of patients with a positive outcome.

\section{Acknowledgements}

1) Icahn School of Medicine, Mount Sinai, New York.

2) Dr. David Knight, Waterbury Hospital, Connecticut.

3) Dr. Monica Sroden, Waterbury Hospital, Connecticut.

4) Liberian College of Physicians and Surgeons.

\section{Conflicts of Interest}

Nil.

\section{Patient's Consent}

Obtained for publication.

\section{References}

[1] MacKay, C. (1966) Perforated Peptic Ulcer in the West of Scotland: A Survey of 5343 Cases during 1954-63. British Medical Journal, 1, 701-705. https://doi.org/10.1136/bmj.1.5489.701

[2] Zelickson, M.S., Bronder, C.M., Johnson, B.L., Camunas, J.A., Smith, D.E., Rawlinson, D., Von, S., Stone, H.H. and Taylor, S.M. (2011) Helicobacter pylori Is Not the 
Predominant Etiology for Peptic Ulcers Requiring Operation. The American Surgeon, 77, 1054-1060.

[3] Bertleff, M.J. and Lange, J.F. (2010) Perforated Peptic Ulcer Disease: A Review of History and Treatment. Digestive Surgery, 27, 161-169.

https://doi.org/10.1159/000264653

[4] Unver, M., Firat, Ö., Ünalp, Ö.V., et al. (2015) Prognostic Factors in Peptic Ulcer Perforations: A Retrospective 14 Year Study. International Surgery, 100, 942-948.

[5] Williams, N., Bullstrode, C. and Connell, R.O. (2008) Stomach and Duodenum in Bailey and Love's Short Practice of Surgery. 25th Edition, Arnold Publishers, London.

[6] Musgrove, J.E. (1955) Posterior Penetrating Gastric Ulcer. Canadian Medical Association Journal, 72, 342-345.

[7] Ellis, B.W. (1995) Perforated and Obstructed Peptic Ulcer Hamilton Baileys Emergency Surgery. 12th Edition, Butterworth Heinemann Ltd., Oxford, 359-362.

[8] Gunshefski, L., Flancbaum, L., Brolin, R.E. and Frankel, A. (1990) Changing Patterns in Perforated Peptic Ulcer Disease. The American Surgeon, 56, 270-274.

[9] Wakayama, T., Ishizaki, Y., Mitsusada, M., Takahashi, S., Wada, T., Fukushima, Y., et al. (1994) Risk Factors Influencing the Short-Term Results of Gastroduodenal Perforation. Surgery Today, 24, 681-687. https://doi.org/10.1007/BF01636772

[10] Wong, C.H., Chow, P.K.H., Ong, H.S., Chan, W.H., et al. (2004) Posterior Perforation of Peptic Ulcer: Presentation and Outcome of an Uncommon Surgical Emergency. Surgery, 135, 321-325. https://doi.org/10.1016/j.surg.2003.11.001

[11] Badawy, A.A. (2016) A Large Posterior Perforation of Gastric Ulcer: A Rare Surgical Emergency. Egyptian Journal of Surgery, 35, 74-76.

https://doi.org/10.4103/1110-1121.176828

[12] Afolayan, M.O., Olajide, T.O. and Balogun, O. (2017) Posterior Perforation of Gastric Ulcer: A Rare Surgical Emergency. Nigerian Journal of Medicine, 26.

[13] Weston-Davies, W.H., Perkiewicz, M. and Szczygiel, B. (1988) Retroperitoneal Extravasation from Perforated Duodenal Ulcer. British Journal of Surgery, 75, 878-879. https://doi.org/10.1002/bjs.1800750916

[14] Chalya, P.L., Mabula, J.B., Koy, M., McHembe, M.D., Jaka, H.M., Kabangila, R., et al. (2011) Clinical Profile and Outcome of Surgical Treatment of Perforated Peptic Ulcers in Northwestern Tanzania: A Tertiary Hospital Experience. World Journal of Emergency Surgery, 6, 31. https://doi.org/10.1186/1749-7922-6-31

[15] Kumar, K., Pai, D., Srinivasan, K., Jagdish, S. and Ananthakrishnan, N. (2002) Factors Contributing to Releak after Surgical Closure of Perforated Duodenal Ulcer by Graham's Patch. Tropical Gastroenterology, 23, 190-192.

[16] Sarda, D.K. and Garg, P.K. (2018) Study of Incidence of Peptic Ulcer Perforation in Young Adults: A Hospital Based Study. International Archives of BioMedical and Clinical Research, 4, 120-123. 